\title{
Estratégias de Enfrentamento do Cotidiano Conjugal
}

\author{
Maria Lúcia Teixeira Garcia ${ }^{2}$ \\ Universidade Federal do Espirito Santo \\ Eda Terezinha de Oliveira Tassara \\ Universidade de São Paulo
}

\begin{abstract}
Resumo
Este estudo analisa estratégias de enfrentamento para a manutenção do casamento, utilizadas por mulheres casadas há mais de 15 anos e pertencentes a estratos econômicos médio e alto, para superação ou minimização de conflitos do cotidiano conjugal. Foram entrevistadas 20 mulheres utilizando roteiro de entrevista semi-estruturada. As entrevistas, gravadas e transcritas, foram analisadas utilizando-se a análise do discurso. Neste artigo analisaram-se as estratégias de ação referida pelas entrevistadas. Entre as mulheres prevaleceu o uso de estratégias diretas (oito), indiretas (quatro mulheres) ou o uso combinado de estratégias diretas e indiretas (oito mulheres). Entre seus maridos, as entrevistadas indicaram o uso de estratégias diretas (treze homens) ou uso combinado de estratégias diretas e indiretas (duas). Em cinco casos enfatizou-se o uso de estratégia indireta, principalmente o silêncio ou o adiamento da busca de solução dos problemas. A estratégia caracterizou-se como uma esperança projectual dessas mulheres de atingirem a superação da condição distópica na direção utópica. A desistência desse jogo implica a adoção de estratégias que assegurem um padrão de comunicação paradoxal no qual os cônjuges ao mesmo tempo que comunicam, evitam comunicar.
\end{abstract}

Palavras-chave: Casamento; relações conjugais; estilos de enfrentamento; mulheres.

\section{Strategies to Face Marital Routine}

\begin{abstract}
This research analyzes strategies used in the carrying out of marriages utilized by women who have been married for over 15 years, from high and middle classes and dwelling in the great Vitória/ES, for the overcoming or reduction of the conflicts in marital daily routine. Semi-structured interviews were used in approaching 20 women. The interviews which were tape recorded and written down, were analyzed in the light of the discourse analysis. In this paper, the strategies indicated by the interviewers were analyzed. It prevailed among women, the direct strategy ( 8 women), indirect (4 women) or both direct and indirect ( 8 women). The interviewers among husbands, indicated the use of direct strategy (13 men) or both direct and indirect (2). In five cases, the women stressed the use of indirect strategies, mainly the silence or the later search for the problem solution. The strategy was characterized as a hope for the women to reach the overcoming towards the utopia. The giving up of this game implicates the adoption of strategies that ensure paradoxical communication in which while the couple communicates, they avoid to communicate.

Keywords: Marriage; relationship marital; styles of to face; women.
\end{abstract}

O presente trabalho apresenta um recorte do projeto de pesquisa intitulado "Da utopia do amor romântico ao cotidiano do casamento: Um estudo sobre estratégias para a manutenção do casamento", financiado pela FAPESP, no qual se analisaram as formas de enfrentamento, utilizadas por mulheres casadas há mais

\footnotetext{
${ }^{1}$ Endereço para correspondência: Rua Chafic Murad, 107/704, Bento Ferreira, 29050-660, Vitória. Espírito Santo. Fax: (27) 3244271. E-mail: tese.vix@zaz.com.br

${ }^{2}$ Estas reflexões são parte do projeto de pesquisa intitulado "Da utopia do amor romântico ao cotidiano do casamento: Um estudo sobre estratégias para a manutenção do casamento", financiado pela Fundação de Amparo à Pesquisa do Estado de São Paulo (1997/7218-7), que resultaram na tese de doutoramento em Psicologia intitulada "Problemas no casamento - A presença utópica do amor romântico", defendida em fevereiro/01, no Programa de Pós-Graduação em Psicologia/USP.
}

de 15 anos e pertencentes a estratos econômico médio e alto, para superação ou minimização de conflitos identificados no cotidiano conjugal. As estratégias foram ali analisadas sob três dimensões: quanto à forma (características da ação no contexto relacional - se direta ou indireta); quanto ao estilo de narrativa (romanceado, dramático e trágico) e, quanto a semântica que configura os argumentos que articulam problemas e estratégias. $\mathrm{O}$ estilo de comunicação utilizado para informar ao outro a insatisfação, o sentido de direção que imprimiram à sua história e a significação que deram às suas palavras formataram todo o conjunto de estratégias.

Essas três dimensões refletem uma aspiração de fundo (a fusão identitária) que tem um papel utópico e sobre o qual nada é questionado porque se coloca na posição de ortodoxia. Pela amplitude dos dados, o trabalho aqui foi 
fracionado, apresentando os resultados obtidos quanto a forma das estratégias referidas pelas entrevistadas.

Parte-se da premissa que a estratégia é definida pela configuração do que é problema que, por sua vez, é delineado a partir da existência de um padrão de desejabilidade projetado para a relação conjugal. Esse padrão de desejabilidade é histórica e socialmente definido e delimita aquilo a que se deve aspirar e aquilo que não se vai alcançar numa relação afetivo-sexual. A aproximação ou distanciamento desse padrão definiria, então, o que é problema e as possibilidades e limites para sua superação. O que fazer e o como fazer são questões que são reflexivamente definidas e estão relacionadas às transformações que vêm ocorrendo no cenário social e que incidem sobre a dinâmica familiar.

\section{Problemas no Casamento}

As transformações que vêm ocorrendo em tempos de modernidade tardia, impõem demandas e ansiedades aos indivíduos, para as quais é preciso buscar respostas de enfrentamento (Giddens, 1993). Lidar com essas ansiedades representaria um problema perene e, entre as principais áreas que homens e mulheres têm procurado algum tipo de alívio ou solução, destaca-se a esfera de relação com amigos, familiares e amantes (Pahl, 1997). Vive-se em um mundo onde "tudo pode acontecer e tudo pode ser feito, mas nada pode ser feito uma vez por todas" (Bauman, 1998, p. 36), o que resulta em insegurança quanto a durabilidade de coisas e de relações. Tal sentimento traria, em si mesmo, uma expectativa de retomada de uma condição desejável, mas ausente, de segurança.

Orientados pela possibilidade de não-durabilidade de uma relação afetivo-sexual, os casais buscariam estabelecer como meta, para seus projetos de conjugalidade, a confiança no parceiro(a). Tal condição não pré-existiria à relação, mas seria trabalhada com o outro em um movimento constante de auto-revelação. A confiança teria a finalidade de "reduzir ou minimizar os perigos aos quais estão sujeitos tipos específicos de atividade" (Giddens, 1991, p. 42) e, entre esses perigos, estaria a possibilidade do(a) companheiro(a) não vir a se comportar como esperado. Essa possibilidade requereria, então, a incorporação de ações passíveis de serem colocadas em prática para evitar que isso venha a ocorrer. O contexto da vida social moderna está aberto a constantes revisões, revisões essas que são requeridas por formas específicas de desenvolvimento prático, moral e cognitivo. Para tanto, desenvolvemos capacidades práticas de resolução de problemas evidenciados nas relações interpessoais.

Nessa interação entre definir o tipo de problema e as alternativas de resolução insere-se, a cada dia, um leque de 'especialistas' responsáveis tanto em identificar o problema que aflige ao outro quanto em encontrar soluções. "(...) tudo e todos parecem querer resolver um 'problema' cada vez mais rebelde ao adestramento" (Costa, 1998, p. 12), qual seja, os conflitos que se estruturam a partir do distanciamento entre a idealização do amor romântico e o cotidiano da relação afetivosexual. O especialista, como mediador, é alguém que combina a capacidade pessoal de compreender com o poder da ciência de tomar decisões corretas (Bauman, 1999; Giddens, 1991). Ele é a ponte sobre o abismo que existe entre as garantias de estar do lado certo (o que só pode ser social) e fazer as opções que alguém deseja (o que só pode ser pessoal).

Os problemas são vividos pelos indivíduos e sua concretude é configurada pelo especialista que define que problemas existem e que soluções devem ser implementadas. Para que um problema exista "eles precisam de um mapeamento socialmente subscrito do mundo vivenciado que os constitui como 'problemas' que pedem 'soluções' (Bauman, 1999, p. 219). Uma situação qualquer só se constitui em problema se soluções socialmente aprovadas estiverem disponíveis e oferecidas. $\mathrm{O}$ argumento aqui é de que o desconforto pessoal (de qualquer ordem) é uma condição remediável e é dever do indivíduo buscar sua superação. "A infelicidade é, portanto, explicável em termos que tornam factível a ação para remediá-la: descrever o desconforto é apontar o método para removê-lo ou aliviá-lo" (Bauman, 1999, p. 220). Tal cenário gera angústia nos indivíduos visto que, se há solução, é inadequado viver com um problema resolvível. Essa rede de dependência aos sistemas peritos ocorre porque, a partir de sua intervenção (direta ou indireta), tais sistemas contribuem para a criação de novos problemas que requerem sua intervenção. "Em vez de alcançar a prometida redução do número de problemas que perturbam o controle da vida, a crescente sofisticação das técnicas especializadas redunda na multiplicação dos problemas (...) Novos problemas continuam a ser produzidos e com eles nova demanda de ação especializada." (Bauman, 1999, p. 226).

Todas essas transformações, aos níveis macro e microssocial, repercutem sobre o projeto de conjugalidade, levando os sistemas periciais a mapearem quais fatores seriam preditivos do sucesso ou insucesso em uma relação conjugal (Féres-Carneiro, 1996; Gottman, Swanson \& Murray, 1999; Gottman \& Silver, 2000; Jablonski, 1996, 1998; Knudson-Martin \& Mahoney, 1996; Lawes, 1999). Tais autores, ao identificarem um conjunto de problemas que envolve, em tempos atuais, os casais, destacam que esses são historicamente 
delimitados, variando conforme o tempo e o contexto em que se inserem. Um exemplo clássico é o acesso das mulheres ao mundo do trabalho fora de casa, que passou de um fato polêmico, no início do século XX, para uma quase unanimidade em termos de reconhecimento de sua importância na virada deste mesmo século (Bruschini, 1994; IBGE, 2000; OIT, 2000; OMS, 2000). Vivendo um período marcado pela certeza de que se tem problemas, competiria aos indivíduos identificá-los e buscar formas de superá-los. Entre definir qual é o problema e a constituição intrínseca deste, cada um acionaria estratégias que, antes de solucionarem, constituirse-iam em manancial semântico de novos problemas.

\section{Estratégia: Um Campo de Opções Possíveis}

Estratégia é um conceito de múltiplos significados. Pode ser definida como "a arte de aplicar os meios disponíveis ou explorar condições favoráveis com vistas a objetivos específicos" (Ferreira, 1993, p. 232). Para Foucault (1982), a palavra estratégia pode ser empregada de três maneiras distintas, podendo designar: os meios empregados para se alcançar um fim; ou, a maneira pela qual um parceiro, em um certo ato do jogo, relaciona o que ele pensa dever ser a ação do outro e o que ele considera que os outros pensam ser o seu; ou ainda, os procedimentos usados em uma situação de confronto para privar o oponente de seus meios de combate e para reduzir seus esforços de resistência. Estes três sentidos estariam associados a situações de confrontação - tais como guerra ou jogos - nas quais o objetivo é agir sobre um adversário de modo a tornar seus esforços impossíveis. Assim, estratégia é definida por escolhas de soluções vitoriosas projetadas para o futuro. Foucault, entretanto, alerta que a palavra estratégia é usada também em outras situações e com sentidos diferentes.

Rocha-Coutinho (1994, p. 127) define estratégia como "formas de um agente social levar uma pessoa a pensar, sentir ou agir de um modo que nem sempre partiria espontaneamente dela", enfatizando que tais estratégias têm caráter relacional e que podem se modificar em função dos atores e/ou contexto nos quais as ações se desenvolvem. Esta autora, ao analisar as estratégias utilizadas por mulheres cariocas de diferentes faixas etárias, identifica dois grandes tipos: a) Formas diretas: ordens, ameaças e reprimendas, cobrança. Aqui ocorreria a explicitação direta da queixa ou da insatisfação que envolve a relação. A comunicação visa a advertir o outro sobre a quebra do projeto desejado com a relação ou a não satisfação de alguma necessidade; e, b) Formas indiretas: jeitinho, chantagem emocional, fragilização do marido e/ou dos filhos. Nesse caso, a pessoa age como

Psicologia: Reflexão e Crítica, 2001, 14(3), pp. 635-642 se não estivesse tentando controlar quando, na verdade, está investindo esforços para controlar o comportamento do outro. Uma das conseqüências da adoção dessa forma de estratégia é que, ao atingir o alvo desejado - a mudança no comportamento do outro - os créditos não seriam atribuídos ao provocador de tal fato. O tipo de estratégia escolhida, seja direta ou indireta, é resultante do papel e do status de cada um dos cônjuges, bem como da distribuição de poder desses na dinâmica familiar. Todo esse conjunto de estratégias constitue-se em modos informais de controlar todo um conjunto de eventos do cotidiano conjugal que afetam o projeto de casamento idealizado.

Numa perspectiva diferente, Knudson-Martin e Mahoney (1998), ao analisarem as estratégias utilizadas por casais recém-casados na busca da igualdade entre os parceiros, analisaram estratégia como ações ou posições que se tomam em relação a algo ou alguém. Nesse sentido, estes autores identificaram dois tipos: a) confrontam-se na busca da resolução do dilema (e, para tal, o casal abre negociação); ou, b) fogem do dilema (a questão é camuflada ou racionalizada). Ao nível do discurso essas estratégias assumem um caráter ora de enfrentamento ativo, ora de enfrentamento "camuflado" através da fragilização (sua ou de outrem). A cada conflito vivenciado o cônjuge insatisfeito vai aprendendo que tipo de estratégia 'funciona' e qual não 'funciona'. Estas estratégias seriam, assim, parte da linguagem - verbal ou não - aprendida pelas pessoas, no decorrer de suas vidas, para lidar com situações concretas do seu dia-a-dia e, como tal, só adquirem sentido em um contexto, em uma sociedade e em um momento histórico determinado (Rocha-Coutinho, 1994, p. 128-129).

Pode-se definir estratégia no âmbito do presente trabalho, como uma ação antecipada na qual a intenção é evitar um resultado em princípio indesejado, por um ou por todos os membros da família. Ela é, assim, aquilo que está sendo veiculado com a intenção de transformar o problema. A escolha de uma dada estratégia depende do problema em cima do qual as opções de resposta serão construídas. Cada membro da díade precisaria definir, inicialmente, o que é esperado ou desejado para a relação. Definindo-se o que se deseja, é possível a eles, consequentemente, identificar aquilo que devem evitar. A análise reflexiva entre o esperado e o indesejado delinearia o problema e as possibilidades (ou não) de superação. Por ter sua delimitação imprecisa, a definição do problema seria inconclusa, fato que acionaria estratégias de características focais e provisórias. A estratégia, tal como o problema, constitui-se, portanto, em manancial semântico de análise da relação conjugal. O objetivo do 
trabalho é identificar e analisar os tipos de estratégias utilizadas por mulheres casadas há mais de 15 anos, pertencentes a estratos socioeconômicos médio e alto da população da Grande Vitória (ES), para manutenção do casamento.

\section{Método}

\section{Participantes}

Envolveu um grupo de 20 mulheres casadas há mais de 15 anos, residentes na Grande Vitória (E.S.), pertencentes a estratos socioeconômicos médio e alto. Utilizou-se a técnica da bola de neve para escolha das entrevistadas (Coleman, 1958; Denzim, 1970). Ao indicar as mulheres para entrevista, cada indivíduo apresentou, para as pesquisadoras, uma avaliação pessoal daquele relacionamento conjugal. Enquadrando nas categorias felizes ou infelizes no casamento, as pessoas faziam inferências sobre o porque de tal opção. Tal enquadramento foi, posteriormente, comparado às autoavaliações feitas por cada entrevistada.

\section{Material e Procedimentos}

Realizou-se entre três a quatro entrevistas semiestruturadas ${ }^{1}$, todas gravadas e transcritas na qual abordou-se a história de seu casamento (namoro, início do casamento, momento atual e a projeção de futuro). Todas as entrevistadas receberam cópias das transcrições de suas entrevistas, momento em que verificavam a adequação do texto produzido por elas. Ao iniciar nova entrevista verificou-se se o texto, produzido no encontro anterior, havia sido lido (Garcia, 1995; Garcia \& Menandro, 1997, 2000). Para análise dos dados utilizouse a análise do discurso (Bakthin, 1992; Orlandi, 1988; Rocha-Coutinho, 1998). Inicialmente fez-se a leitura cuidadosa das entrevistas para a análise temática, a fim de detectar os tópicos gerais que estas apresentavam. Todo esse processo resultou na identificação de categorias por derivação empírica. Posteriormente, realizou-se a fragmentação, ou seja, nova análise segundo os temas emanados da anterior, para estabelecimento da ordem de importância e a seqüência dos temas encontrados. A reaplicação das categorias resultantes da primeira etapa objetivou identificar a adequação dessas ao texto. Finalmente, realizou-se o reagrupamento das respostas,

\footnotetext{
1 - A variação no número de contatos (3 ou 4) foi determinada pela maior ou menor disponibilidade das entrevistadas em agendar novos encontros (as entrevistas ocorreram ao longo de 2 anos). Assegurou-se que todas as questões contidas nos roteiros de entrevista fossem respondidas e, posteriormente, lidas por elas.
}

destacando-se o tipo de estratégia utilizada para o enfrentamento das situações de conflito no casamento (Queiroz, 1991). Foram utilizados, ainda, os elementos contraditórios presentes no discurso, as mudanças na entonação empregada na narração e os argumentos utilizados na definição do tipo de estratégia empregada. As entrevistadas foram distribuídas em três grupos: mulheres felizes e satisfeitas com o casamento, mulheres felizes e insatisfeitas e, mulheres infelizes com a convivência conjugal. Os tipos de estratégias foram divididas em formas diretas e formas indiretas (Rocha-Coutinho, 1994). Utilizaram-se letras do alfabeto para identificação das respondentes. A idade média das mulheres foi de 48 anos (mínima de 35, máxima de 56 anos). Elas casaram-se na faixa etária entre os 18 e os 33 anos (média de 23 anos). O maior tempo já transcorrido de casamento foi de 34 anos e o menor de 16 (média de 24 anos). Cinco mulheres se casaram na década de 60 (entre os anos de 64 e 69), 12 mulheres na década de 70 (entre os anos de 71 e 80 ) e 3 mulheres se casaram na década de 80 (entre 81 e 82 ).

\section{Resultados e Discussão}

Entre as mulheres prevaleceu o uso de estratégias diretas (8), uso combinado de estratégias diretas e indiretas (8 mulheres), ou indiretas (4 mulheres). O tipo de estratégia escolhida por cada uma destacou uma seleção de ações para superação ou redução do impacto negativo de situações indesejadas para a díade. Ao indicarem as estratégias utilizadas por seus companheiros, destacaram o uso de estratégias diretas (13 homens) ou uso combinado de estratégias diretas e indiretas (2). Em 5 casos, enfatizou-se o uso de estratégia indireta, principalmente o silêncio ou o adiamento da busca de solução dos problemas. Ser direta, ou usar de subterfúgios (no caso feminino), foi valorado positivamente visto ser expressão de sua esperteza no trato com o parceiro. Em contrapartida, a diretividade adotada por seus parceiros evidenciava intolerância, impaciência e objetividade. O significado atribuído às estratégias esteve também relacionado à avaliação que faziam de seus casamentos. Observou-se que entre aquelas entrevistadas que avaliavam negativamente seus relacionamentos $(\mathrm{A}, \mathrm{B}, \mathrm{L})$, o uso alternado de estratégias diretas e/ou indiretas evidenciava uma ação de esquiva ao diálogo, à medida que identificavam a impossibilidade de mudança na qualidade do vínculo conjugal. Com um cotidiano marcado pela quebra do projeto de casamento desejado, o momento atual desnudava a impossibilidade de comunicar sua insatisfação ou a inadequação de tal comunicação, visto que o outro não se comportará como 
desejado. A avaliação negativa sustentava-se pela presença de relações extraconjugais (estáveis ou eventuais), insatisfação na relação sexual e reduzida, ou inexistente, participação masculina na renda familiar. Não tendo porque lutar, o conflito não gerenciado é camuflado a partir da fragilização do companheiro e pela impossibilidade de quebra do vínculo conjugal.

"Tem hora que ele verbaliza o fato, se acontecesse isso hoje de novo ele não faria de novo, realmente não vale o preço que ele pagou, ora ele tá muito machucado, muito aborrecido..." (entrevistada A, 51 anos, 27 anos de casamento, indicada e indicando-se como infeliz).

A comunicação é associada a um 'nhenhenhem', na qual cada um dirige lamúrias ao outro, não informando, adequadamente, quais são os problemas. Tais lamúrias permitiriam, ao casal, camuflar ou fugir do problema.

“... estávamos sempre juntos, estávamos juntos, mas não compartilhávamos nada, a não ser a casa, até que em determinado momento eu falei: a gente não conversa, a gente não sai um com o outro. E ele: - "talvez por isso estejamos juntos há tanto tempo" (entrevistada B, 48 anos, 27 anos de casamento, indicada e indicando-se como infeliz).

A alternância entre estratégias indiretas e diretas permitia-lhes, ao mesmo tempo evitar o diálogo e endereçar ao cônjuge ameaças quanto ao risco a que o projeto de convivência conjugal estava exposto. Avaliando negativamente seu cotidiano conjugal, estas mulheres denunciavam que suas estratégias assumiam a função de fuga do dilema. Tal dilema configurava-se pela exclusão da condição de felizes no casamento e pelo não-desejo de rompimento do vínculo conjugal. Suas estratégias explicitavam, assim, uma perspectiva distópica de conjugalidade. Desejavam, mas sabiam que não conseguiriam alcançar, a condição de felizes no casamento. Tal processo não excluía que o alvo, para elas inalcançável, era uma condição identificada como presente no discurso de outras mulheres. A presença de um elevado nível de satisfação na relação conjugal, no discurso de outras mulheres, reafirmava sua exclusão desse grupo.

As mulheres ditas felizes dividiam-se entre as ditas felizes e satisfeitas com o casamento, e as felizes e insatisfeitas com o momento atual vivido pela família. $\mathrm{O}$ que diferiu um grupo do outro foi a avaliação que faziam do presente. No grupo de mulheres ditas felizes e satisfeitas com o casamento, as queixas referiam-se ao cotidiano da casa. 'É o 'controle remoto', 'o ronco', 'O ar-condicionado', 'as preocupações do trabalho dele', 'o temperamento dele', etc. No segundo grupo - mulheres felizes, porém insatisfeitas - as queixas oscilaram entre ' $O$ temperamento dele', 'divergências na educação dos filhos', ' maior sucesso profissional feminino', entre outras. Para tais situações a comunicação poderia ser ora direta (4 mulheres), ora indireta (2) ou, ainda, ora a conjugação de ambos (3 mulheres). As variações eram determinadas por uma avaliação quanto ao momento em que tinham que agir e o impacto de suas ações sobre o companheiro.

"Eu acho que quando você conhece as pessoas que você tá se relacionando, e que você quer que dê certo aquilo que você tá construindo, você vai ajeitando as coisas, entendeu? Por exemplo: meu marido sabe, eu já falei pra ele que eu detesto passar roupa. Então, pra não ... Porque que ele vai, se ele sabe que eu detesto que eu fico danada da vida quando passo uma pra mim, por quê que ele, sabendo disso - acho que é o que ele pensa, não sei - por que é que ele vai ... me dar roupa pra passar, se ele sabe que ele vai me magoar, entendeu?” (entrevistada P, 46 anos, 20 de casamento, indicada e indicando-se como feliz).

As mulheres felizes, mas insatisfeitas, apontaram uma diferença entre a imagem exterior apresentada pelo casal e o cotidiano. Essa discrepância é referida como complexa, já que nem sempre podem comunicar aos outros suas insatisfações.

"Todos acham que ele é um marido perfeito, os homens acham ele bobo porque ele fica dentro de casa, e se um dia eu me separar dele eu vou ser a ruim e ele vai ser o bom. Vão dizer que eu sou maluca de largar um homem daqueles, que vive pra dentro de casa; por isso que eu falo com você que eu não gosto de comentar com as pessoas esse outro lado, porque eles não entendem essa sutileza, questão de elaborar um relacionamento, a imagem que as pessoas têm do meu casamento é de um casamento equilibrado, e ele é equilibrado mas acho que eu vou mais longe, essa imagem que passa pras pessoas..." (entrevistada I, 43 anos, 23 de casamento, indicada como feliz, mas indicando-se como feliz porém insatisfeita). As estratégias diretas (4 respondentes) objetivavam comunicar suas insatisfações em momentos que avaliavam serem adequados para tal expressão. Em tais situações, suas atitudes eram interpretadas, por seus parceiros, como expressão de 'gênio forte' e, via de regra, resultava em embates cujo resultado nem sempre avaliado como esperado.

“... esse fato de ruminar os problemas, isso aumentou com o passar dos tempos. Eu já fui muito mais explosiva, mais direta e você vai envelhecendo e aprendendo que a melhor solução não é esse...." (entrevistada O, 47 anos, 19 de casamento, indicada como feliz, referindo-se como insatisfeita com a relação).

O uso da estratégia indireta nesse grupo (2 entrevistadas), permitia-lhes abordar questões sem que suas insatisfações fossem, de fato, comunicadas ao parceiro. Uma das conseqüências da adoção dessa forma de estratégia é que, ao atingir o alvo desejado - a mudança no comportamento do outro - os créditos eram atribuídos ao outro e não a elas - provocadoras de tal fato. 
"Então tem que ser na hora exata, sim, saber tocar no ponto nevrálgico na hora certa; aí aquilo vai minando o coração dele né, e depois aí vai dando certo né, e aí eu consigo chegar na meta e nem sempre é pelos caminhos que eu quero..." (entrevistada E, 50 anos, 30 de casamento, indicada como feliz e indicando-se como insatisfeita).

A charadinha, por sua sutileza, evidencia uma ação, denominada por Rocha-Coutinho (1994) de atrás dos panos, na qual a mulher se mantém em uma posição fragilizada ante seu companheiro o que lhe permite, estrategicamente, planejar e articular todo um conjunto de ações que visam exercer controle sobre o comportamento dele.

"Eu acho que não, que ele não percebeu na época, né" (entrevistada D, 52 anos, 34 anos de casamento, indicando-se e sendo indicada como feliz). no conflito. Porque eu acho, eu tenho comigo de que quando você fala com a cabeça quente, você pode falar coisas que depois você se arrepende. E ele também tem a mesma, esse mesmo procedimento" (Entrevistada S, 55 anos, 34 anos de casamento, indicada e indicando-se como feliz).

Todo este leque de ações configurariam um planejamento estratégico que incorporaria experimentações feitas pela díade no trato com o parceiro(a) e também as orientações fornecidas pelos sistemas periciais. As estratégias, como formas de ação, teriam como substrato uma relação dialética entre o projeto de conjugalidade e o contexto social. As mudanças ocorridas em tempos de modernidade tardia imprimiriam aos casais o desafio de buscarem uma relação que, para se manter, requer negociações e barganhas entre os membros da díade.

Tabela 1. Correlação entre Estratégia Utilizada e Avaliação do Casamento

\begin{tabular}{lcccccc}
\hline & \multicolumn{2}{c}{$\begin{array}{c}\text { Só Estratégia } \\
\text { Direta }\end{array}$} & \multicolumn{2}{c}{ Só Estratégia Indireta } & \multicolumn{2}{c}{$\begin{array}{c}\text { Estratégia Direta } \\
\text { e Indireta }\end{array}$} \\
\hline Mulheres felizes e satisfeitas & $N$ & $\%$ & $N$ & $\%$ & $N$ & $\%$ \\
Mulheres felizes e insatisfeitas & 04 & 20 & 02 & 10 & 03 & 15 \\
Mulheres infelizes & -20 & 02 & 10 & 02 & 10 \\
\hline
\end{tabular}

Uma exploração estratégica do cotidiano permite a cada membro da díade avaliar e selecionar a melhor forma de abordar o parceiro, em função de variáveis que incidem sobre a família em um dado momento. Essa escolha, pautada numa antecipação da reação do outro, é feita dentro de um leque de opções possíveis.

“... quando ele está, assim, irritado, que às vezes eu evito falar naquela hora, eu percebo que é até melhor ficar calada no momento e, depois, numa outra oportunidade a gente se esclarece com mais calma" (entrevistada C, 44 anos, 17 anos de casamento, indicada como feliz, referindo-se como insatisfeita).

Em contrapartida, as estratégias adotadas por seus parceiros, delineiam expectativas de seu papel sexual, ou seja, um discurso direto e objetivo. Comunicando diretamente, ele advertiria a companheira quanto à ameaça de quebra do projeto desejado de relacionamento ou a inadequação de atitudes adotadas por ela.

"... ele bota tudo pra fora o que sente, mas no fundo ele é bom ..." (entrevistada E, 50 anos, 30 anos de casamento, indicada como feliz e indicando-se como insatisfeita).

Outra alternativa, no caso da adoção de estratégias indiretas por parte dos homens, foi atribuído à similaridade de comportamento dos membros do casal.

"Muito com o silêncio e ele também. Depois que passa (...) que a gente já voltou ao normal, a gente fala sobre o assunto. Mas a gente não fala quando está, vamos dizer assim,
Tais barganhas explicitariam qual o projeto de conjugalidade almejado e este, por sua vez, definiria os pilares de convergência ou divergência entre ambos. Divergências no projeto culminariam tanto na identificação de problemas quanto no desafio da forma de comunicar ao outro sua insatisfação.

Ao perseguirem um ideal de fusão identitária, estas mulheres vivem um momento ambíguo, desejam, mas não conseguem, um padrão de comunicação que se aproxime do modelo almejado. A utopia do amor romântico foi o farol iluminador de soluções estratégicas visto que definia aquilo que era ou não problemático e, assim, o quanto ameaçava (ou não) o seu projeto conjugal. $\mathrm{O}$ alvo direcionava-se para um futuro, projetado como igual (feliz e satisfeita) ou diferente (feliz, mas insatisfeita) do momento atual. Entre as mulheres ditas felizes e insatisfeitas, a utopia do amor romântico penetra nelas através de sua força distópica, qual seja, 'analiso que não estou e desejando estar, me comporto como se pudesse vir a atingir'.

As mulheres ditas infelizes denunciam, através de suas narrativas, como a quebra do contrato de exclusividade, a indefinição quanto a perenidade do relacionamento e a inexistência de prazer sexual, inviabilizam e excluem da posição desejada (ser feliz). O afastamento desse ideal almejado fazem-nas desenvolver um discurso com tons 
trágicos, no qual o cotidiano é desenhado por uma iminente colisão identitária, na qual projetos paralelos convivem e evitam o embate, visto que a separação é retratada como indesejada.

\section{Considerações Finais}

Estratégia, como uma ação de enfrentamento de problemas emanados do cotidiano conjugal, caracterizouse ora como uma esperança projectual das entrevistadas de atingirem a superação da condição distópica em que se identificavam na relação conjugal para uma direção utópica (mulheres felizes, porém insatisfeitas), ora de redução das ansiedades geradas determinada pela impossibilidade de saída da posição distópica (mulheres infelizes). A permanência ou desistência dessa esperança resulta na adoção de estratégias diferenciadas. Para as mulheres infelizes, a busca de um padrão de comunicação paradoxal assegura ao casal a manutenção do vínculo conjugal. As mulheres ditas felizes no casamento ocupam uma posição almejada pelas demais e, ao mesmo tempo, reafirmam a esperança de que é possível, mesmo que cada vez se acredite menos, alcançar um nível satisfatório no relacionamento conjugal. Esses três grupos configurariam a existência de um dipólo feliz/infeliz no qual cada uma se identificou. Vivemos numa sociedade em que a construção da identidade e da subjetividade organizam-se dentro de uma lógica dialética de inclusão/ exclusão, na qual a mediação afetiva/cognitiva estabelece as condições para que cada um avalie se está ou não incluído. Neste jogo de busca de permanência de inclusão e luta para sair da condição de exclusão é que se definem os contornos da história de vida de cada indivíduo.

Entre as entrevistadas, o êmulo inclusão/exclusão oscilou entre as posições feliz e infeliz no casamento. Sua inclusão em uma posição ou outra ocorreu em função da pertinência ou não a um grupo representativo de um padrão de desejabilidade. Esse padrão de desejabilidade, pautado na utopia do amor romântico, define a fusão identitária como condição para a produção de condições de convivência conjugal baseadas na exclusividade, na durabilidade e no prazer sexual. O êmulo oscilaria assim, entre a proximidade ou o afastamento da utopia do amor romântico. Com isso, o jogo utopia/distopia permitiria incluir-se ou almejar a inclusão na condição de felizes no casamento visto que no presente, ou no futuro, as condições requeridas estarão asseguradas. À medida que esse êmulo não oscila mais entre uma posição ou outra, perde-se o nexo de possibilidade de inclusão dialética e o resultado é a condição de excluído. A exclusão do padrão de desejabilidade para a relação conjugal resultava,

Psicologia: Reflexão e Crítica, 2001, 14(3), pp. 635-642 entre essas mulheres, a impossibilidade de corresponderem (nem no presente, nem no futuro) a uma imagem de desejabilidade apontada pelo exterior.

Antecipando o risco iminente por que passa o projeto de conjugalidade (problema destacado amplamente por pesquisadores das mais diferentes áreas), as entrevistadas descreveram, reflexivamente, todo impacto que essas transformações impõem ao seu cotidiano familiar. De um projeto estável (perenidade da relação conjugal), os casais hoje incorporam em seus discursos, uma perspectiva distópica (sabem que poderá não durar). Riscos e perigos são mapeados pelos casais, riscos e perigos esses que requerem a implementação de ações que se referem à necessidade de fazer algo para a relação perdurar. As estratégias, que são reais, materiais, indicam qual seja o problema vivido por cada casal em seu cotidiano. Nas narrativas dessas mulheres uma questão foi enfatizada por todas: "não existe casamento sem problemas". Tal argumento configuraria então duas questões: primeiro a antecipação de que 'há problema' e, segundo, que algo pode ser feito para que 'não haja mais problema'.

\section{Referências}

Bakhtin, M. (1992). Estética da criação verbal. São Paulo: Martins Fontes. Bauman, Z. (1998). O mal-estar da pós-modernidade. Rio de Janeiro: Jorge Zahar.

Bauman, Z. (1999). Modernidade e ambivalência. Rio de Janeiro: Jorge Zahar. Bruschini, C. (1994). O trabalho da mulher no Brasil: Tendências recentes. Em H. I. B. Saffiotti \& M. Munõz-Vargas (Orgs.), Mulher brasileira é assim (pp. 63-94). Rio de Janeiro: Rosa dos Tempos: NIPAS; Brasília, D.F.: UNICEF.

Coleman, J. (1958). Relational analysis: The study of social organization with survey methods. Human Organization (Spring), 17, 28-36.

Costa, J F. (1998). Sem fraude nem favor: Um estudo sobre o amor romântico. Rio de Janeiro: Rocco.

Denzim, N. K. (1970). The research act: A theoretical introduction to sociological methods. Chicago: Aldine.

Féres-Carneiro, T. (1996). Família: Diagnóstico e terapia. Petrópolis, RJ: Vozes.

Ferreira, A. B. H.(1993). Minidicionário da Lingua Portuguesa. Rio de Janeiro: Nova Fronteira.

Foucault, M. (1982). The subject and power. Em H. L. Dreyfus \& R. Rabinow (Orgs.), Michel Foucault: Beyond structuralism and hermeneutics (pp. 208-226). Chicago: The University of Chicago Press.

Garcia, M. L. T. (1995). Relações conjugais e conjugação de conflitos: O cotidiano de mulheres de alcoolistas. Dissertação de Mestrado não-publicada. Curso de Pós-Graduação em Psicologia, Universidade Federal do Espírito Santo. Vitória, Espírito Santo.

Garcia, M. L. T. \& Menandro, P. R. M. (1997). A utilização de práticas supersticiosas por mulheres de alcoolistas. Revista da ABP-APAL, 2(19), $39-44$.

Garcia, M. L. T. \& Menandro, P. R. M. (2000). A relação conjugal de mulheres de alcoolistas: Um estudo qualitativo. Jornal Brasileiro de Psiquiatria, 9, 343-350.

Giddens, A. (1991). As conseqüências da modernidade. São Paulo: UNESP.

Giddens, A. (1993). A transformação da intimidade: Sexualidade, amor e erotismo nas sociedades modernas. São Paulo: Editora da Universidade Estadual Paulista. 
Gottman, J., Swanson, C. \& Murray, J. (1999) The mathematics of marital conflict: Dynamic mathematical nonlinear modeling of newlywed marital interaction. Journal of Family Psychology, 13(1), 3-19.

Gottman, J. \& Silver, N. (2000). Sete princípios para o casamento dar certo. Rio de Janeiro: Objetiva.

Instituto Brasileiro de Geografia e Estatística (2000). Indicadores sociais mínimos. http://www.sidra.ibge.gov.br.

Jablonski, B. (1996). Papéis conjugais: Conflito e transição. Em T. F. Carneiro (Org), Relação amorosa, casamento, separação e terapia de casal (pp. 113-123). Rio de Janeiro: Associação Nacional de Pesquisa e Pós-Graduação em Psicologia.

Jablonski, B. (1998). Até que a vida nos separe: A crise do casamento contemporâneo. Rio de Janeiro: Agir.

Knudson-Martin, C. \& Mahoney, A. R. (1996). Gender dilemmas and myth in the construction of marital bargains: Issues for marital therapy. Family Process, 35, 137-153.

Knudson-Martin, C. \& Mahoney, A. R. (1998). Language and processes in the construction of equality in new marriages. Family Relations: Interdisciplinary Journal of Applied Family Studies, 47(1), 81-91.

Lawes, R. (1999). Marriage: An analysis of discourse. British Journal of Social Psychology, 38, 1-20.
Organização Internacional do Trabalho (2000). La mujer y el mundo del trabajo: Los costos sociales de un verdadero progreso. http:://www.ito.org/public/ spanish.

Organização Mundial de Saúde (2000). Gender and health a technical paper. http://www.who.whd/gendertecn.

Orlandi, E. P. (1988). Discurso e leitura. São Paulo: Cortez.

Pahl, R. (1997). Depois do sucesso: Ansiedade e identidade fin-de-Siècle. São Paulo: Fundação Editora da UNESP.

Queiroz, M. I. (1991). Variações sobre a técnica de gravador no registro da informação viva. São Paulo: T. A. Queiroz.

Rocha-Coutinho, M. L. (1994). Tecendo por trás dos panos: A mulher brasileira nas relações familiares. Rio de Janeiro: Rocco.

Rocha-Coutinho, M. L. (1998). A análise do discurso em Psicologia: Algumas questões, problemas e limites. Em L. Souza, M. F. Q. Freitas \& M. M. P. Freitas (Orgs.), Psicologia: Reflexões (im)pertinentes (pp. 317-345). São Paulo: Casa do Psicólogo.

Recebido: 29/12/2000

Revisado: 20/04/2001

Aceite Final: 21/06/2001

Sobre as autoras

Maria Lúcia Teixeira Garcia é Assistente Social, Doutora em Psicologia Social pela Universidade de São Paulo, professora do Departamento de Serviço Social da Universidade Federal do Espírito Santo.

Eda Terezinha de Oliveira Tassara é Doutora em Psicologia pela Universidade de São Paulo, professora do Programa de Pós-Graduação em Psicologia Social da Universidade de São Paulo. 